\title{
The Impact Of Course Scheduling On Student Success In Intermediate Accounting
}

\author{
Linda G. Carrington, Sam Houston State University, USA
}

\begin{abstract}
Cognitive psychology research, as well as educational psychology research, suggests that learning is enhanced when new subjects are presented in spaced-out sessions rather than compressed into fewer, longer sessions (the "spacing effect"). This would suggest that students should learn better when taking courses that are scheduled over longer time periods (two or three days per week over a long semester) rather than in an intensive (one day per week) or compressed (summer session) format. This research investigates whether the spacing effect exists for students in Intermediate Accounting classes. Specifically, this research examines student performance in Intermediate Accounting courses offered in four different scheduling formats including one, two, and three days per week over traditional long semesters, as well as during compressed four-week summer sessions. A significant association between course schedule and student performance is found to exist. The effect of student age and gender on this association is also explored. Results identify one scheduling option which appears to be a particularly poor schedule for Intermediate Accounting, as well as particular characteristics of students who might be more likely to have difficulty with this schedule. Results should be of interest to university administrators responsible for making scheduling decisions, to faculty members teaching under different course schedules, and to individual students planning their class schedules.
\end{abstract}

Keywords: Intermediate accounting, course schedule, spacing effect, accounting education, compressed schedule, intensive schedule, accounting student success

\section{INTRODUCTION}

ognitive psychology research, as well as educational psychology research, suggests that learning is enhanced when new subjects are presented in spaced-out sessions rather than compressed into fewer, longer sessions (the "spacing effect"). This would suggest that students should learn better when taking courses that are scheduled for more sessions over longer time periods (two or three days per week over a long semester) rather than in an intensive (one day per week) or compressed (summer session) format. This paper reports the results of research into the existence of the spacing effect in Intermediate Accounting. If the spacing effect exists, one would expect students taking intermediate accounting two or three days per week over a long semester to perform better than students taking the course one day per week or in the summer. A review of existing literature is provided first, followed by a description of this study, hypothesis development and testing, and finally interpretation of the results.

\section{LITERATURE REVIEW}

Previous research into the spacing effect provides mixed results. Most of the cognitive psychology literature supports the existence of the spacing effect. In contrast, much of the educational psychology research suggests that students taking a class in a compressed or intensive scheduling format will perform as well, and sometimes even better, than students in traditional scheduling formats. This research does suggest, however, that there are some courses which are not well suited for compressed or intensive scheduling. These courses include those which are part of a sequence and therefore require the students to make use of prior knowledge as well as courses which require more analysis than memorization. Relevant literature can be placed into three categories; cognitive psychological research on the "spacing effect," educational research applying the spacing effect theory to 
higher education in general, and finally, research which addresses the affect of course scheduling on student performance in accounting, business or similar types of higher education courses.

\section{Cognitive Psychology Research}

There is a very large body of psychological research which focuses on a phenomenon known as the spacing effect. The spacing effect "refers to the finding that for a given amount of study time, spaced presentations yield substantially better learning than do massed presentations" (Dempster, 1988, p. 627). In other words, the spacing effect suggests that reviewing information or practicing new skills periodically, over several weeks or months enhances retention. Specifically, research has found that when learning sessions and practice periods are spaced out over a given period of time rather than compressed together in time, long-term memory of the new information/task is improved. There have been many studies, conducted over many years, which focus on this phenomenon including Donovan \& Radosevich, 1999; Foma, 1983; Gay, 1973; Krug, Davis, \& Glover, 1990; Pyle, 1913; Reynolds \& Glaser, 1964, to name a few. These studies consistently support the existence of the spacing effect.

\section{Educational/Psychology Research}

The finding of a spacing effect has obvious implications for educators. The spacing effect would suggest that student learning will be enhanced by introducing/teaching course material in regular increments spread out over a longer time period. For colleges and universities, this would tend to suggest that student learning/success will be greater in a course delivered several times a week over many weeks (a traditional long semester) than in a course which is compressed into a much smaller time period (a few weeks or only one time per week). Accordingly, there have been many research studies published in the educational psychology literature which specifically address the effects of intensive and compressed courses in higher education (Brett, 1996; Brookes, 1985; Daniel, 2000, Doyle \& Yantis, 1977; Henebry, 1997, Kanun, Ziebarth \& Abrahams, 1963; Kirby-Smith, 1987; Logan \& Geltner, 2000; Scott, 1996; Scott \& Conrad, 1991; Seamon, 2004; Studdard, 1975; Wallace, 1972). Surprisingly, many of these studies produced results which are inconsistent with the spacing effect. Daniel (2000) prepared a meta-analysis which reviewed prior research comparing the effectiveness of compressed courses with that of traditionally delivered courses. Based on this extensive literature review, Daniel concluded that compressed courses result in student achievement/learning that equals and sometimes even surpasses that of traditional, non-compressed courses. The conclusion applied to both short-term and long-term learning and held true across several disciplines. Scott \& Conrad (1991) also performed an extensive literature review on this topic. They reviewed research on traditionally delivered courses, summer courses, interim session courses and weekend courses and found that student learning in compressed courses, again, was equal to or exceeded learning in traditional courses.

In contrast, there have been some studies on class scheduling which do confirm the existence of a spacing effect (that distributed practice is significantly superior to massed practice). Smith and Rothkopf (1984) found that presenting lessons in one day was less effective that presenting those same lessons over 4 days. Specifically they found that the effect of massing the data together in one day was primarily on the short-term retrieval of facts rather than on long-term learning. Brookes (1985) found that scheduling patterns made no significant difference in students' chances of passing a writing course, although they found that it may have affected their ability to attain a high grade. Also, noteworthy is Logan and Geltner (2000). Although they concluded that compressed classes contributed to student success, they also suggested that classes that met more often might be better for student learning.

\section{Course Scheduling Research - Accounting, Business or Similar Courses}

There are some, although noticeably fewer, published studies on this topic which use accounting, business or other similar courses. Gallo \& Odu (2009) examined the relationship between scheduling of classes (3, 2, or 1 day per week) and achievement in college algebra and found that student performance was lower when taking the course one day per week. This study is particularly relevant to the current one because in college algebra, much like in accounting, concepts are not presented in isolation of one another but rather are presented in a sequence and require the student to use prior knowledge. Gallo \& Odu suggest that lower student performance in the one time per week schedule may be due to the fact that the students were forced to rely more on rote learning and did not have 
adequate time to make meaningful connections with prior knowledge. In contrast, because information in the two and three days per week classes was presented in smaller pieces and sufficiently spaced, students in those classes may have been better able to make the required connections.

There are only a few studies which focus on the impact of class scheduling on business courses. Henebry (1997) studied the impact of class schedule on students enrolled in a Corporate Finance course and found higher pass rates and lower drop rates for classes meeting two or three times per week as compared to classes meeting only once per week. These findings are consistent with spacing effect theory and with those of Gallo \& Odu (2009) noted above.

In economics, there have been conflicting results. Van Scyoc \& Gleason (1993) compared students in a 14 week semester and a 3 week course for microeconomics. Overall, this study concludes that students in the compressed courses learned and retained at least as much knowledge as students in the traditional length courses. However, Petrowsky (1996), who also examined microeconomics courses, found diminished academic performance in those areas of economics that stress comprehension and analysis over mere recall. Petrowsky found that summer students (compressed) did better than spring students (traditional schedule) on tests from the first half of the course which involved simple recall of information. However, they performed worse on the tests in second half of course which involved comprehension, application, and analysis. This research recommended abandoning the two week format for economics classes. Petrowsky's finding that compressed courses were not good for courses which required more comprehension and analysis is particularly relevant for the current study of Intermediate Accounting which requires a high level of analysis.

Finally, there has been one study which used accounting courses as its focus. Caskey (1994) examined results for students enrolled in Accounting I and II (principles of accounting) which were offered under both the traditional model and an intensive format. The results showed no statistical difference in mean course grades between formats.

\section{STUDY DESCRIPTION}

The current study was conducted at a 4-year public university located in Texas, with an enrollment of approximately 17,000 students. The College of Business at this university is accredited by the AACSB. This study examines the performance of all students enrolled in Intermediate Accounting I or Intermediate Accounting II during the period beginning Fall 2006 and continuing through Summer 2009. This includes three fall, three spring, and three summer semesters and a total of 2,012 enrollments. Intermediate I and Intermediate II were both included in the study because of their similarities. Both courses are part of a sequence, both are upper level, both require more analysis than memorization and both were taught by the same set of professors at this university. Therefore, it is expected that if a spacing effect exists, it would affect students in both courses in a very similar manner. For this reason, both courses were included in the study and are referred to in this paper collectively as Intermediate Accounting. Intermediate enrollment during this period was approximately evenly mixed in terms of gender with $51.33 \%$ females and $48.67 \%$ males. Ethnicity of the enrollments was as follows: $69.6 \%$ white, $12.9 \%$ black, $11.6 \%$ Hispanic, and 5.9\% other. Most students in this group (74.9\%) were of traditional college age (defined as 25 years old or less) with a sizable minority (25.1\%) of nontraditional age students (over age 25). $88.9 \%$ completed the course and received a grade (A,B,C,D,F), while $11.1 \%$ did not complete the course (withdrew, resigned or dropped).

During the period of this study, Intermediate Accounting was offered according to a variety of scheduling options. Traditional schedules include two or three days per week for a 15 -week fall or spring semester. The two days per week schedule met on Mondays and Wednesdays or on Tuesdays and Thursdays for 75 minutes each day while the three days per week schedule met on Mondays, Wednesdays and Fridays for 50 minutes per day. In addition, during the fall and spring semesters Intermediate Accounting was offered one day per week for 150 minutes. Finally, Intermediate Accounting was also offered in compressed 4-5 week summer sessions where the course met every day for two hours.

Two tenured faculty members, each with over fifteen years' experience teaching Intermediate Accounting at this university, taught $80 \%$ of these Intermediate classes, with the other $20 \%$ of the classes taught by a 
combination of tenured faculty and instructors. The two faculty members that teach most of the Intermediate courses closely coordinate with each other and with the other faculty who teach the remaining courses, so that the topics covered, the general approach used and the overall level of difficulty of these classes is very similar. There was also a common textbook which was used for all classes in this study period. Thus, concern about the effect of different teachers on student performance is significantly diminished.

\section{RESEARCH QUESTIONS AND HYPOTHESIS TESTING}

The first research question in this study can be stated as follows: Does the manner in which Intermediate Accounting courses are scheduled affect student performance? For purposes of this study, performance is measured by the final course grade received. Accordingly, the first null hypothesis is:

H1o: Student grades in Intermediate Accounting are not associated with course schedule.

Table 1a shows the number (and percentage) of students receiving each possible grade in each course schedule. A grade of "Q" represents students who did not finish the course due to dropping the course, withdrawing or resigning.

Table 1a: Student Grades and Course Schedule

\begin{tabular}{|c|c|c|c|c|}
\hline Course Grade & \multicolumn{4}{|c|}{ Course Schedule } \\
\hline & 1 Day/Week & 2 Days/Week & 3 Days/Week & Summer \\
\hline A & 19 & 142 & 19 & 41 \\
\hline B & $7.8 \%$ & $11.6 \%$ & $9.1 \%$ & $12.1 \%$ \\
\hline C & 63 & 273 & 34 & 63 \\
\hline & $25.8 \%$ & $22.4 \%$ & 64 & $18.6 \%$ \\
\hline D & 68 & 341 & $30.6 \%$ & $33.9 \%$ \\
\hline F & $27.9 \%$ & $28.0 \%$ & 29 & 55 \\
\hline & 37 & 211 & $13.9 \%$ & $16.2 \%$ \\
\hline & $15.2 \%$ & $17.3 \%$ & 16 & 31 \\
\hline & 26 & 140 & $7.7 \%$ & $9.1 \%$ \\
\hline
\end{tabular}

To test for the association between course schedule and course grade, a chi square test was used to test for independence of the variables (lack of association). A chi-square test was used because both variables, course schedule and course grade, are categorical. A significance level of .05 was used for all hypothesis testing. The result of the chi-square test on this data is reported in Table $1 \mathrm{~b}$.

Chi-Square Test of Table $1 b$

\begin{tabular}{|l|c|c|c|}
\hline & Value & df & $\begin{array}{c}\text { Significance Level } \\
\text { (p-value) }\end{array}$ \\
\hline Pearson Chi-Square & 47.602 & 15 & .000 \\
\hline
\end{tabular}

The resulting chi-square statistic of 47.602 is significant at the .05 level, which indicates that there is a significant association between course schedule and course grades. Thus, we must reject H1o, the null hypothesis of no association.

Having established the existence of an association, it is now of interest to know if one of these schedules is optimal for Intermediate Accounting. The second research question of this study can be stated as follows: Is there a significant difference in student grades in Intermediate Accounting between the four different course schedules? In other words, are there significantly more A's in a one day per week schedule, or more D's in the two days per week schedule, etc. Since there are six possible grades, this results in a set of six additional null hypotheses as follows. 
H2o: There are no significant differences in the percentage of A's across the different course schedules.

H3o: There are no significant differences in the percentage of B's across the different course schedules.

H4o: There are no significant differences in the percentage of C's across the different course schedules.

H5o: There are no significant differences in the percentage of D's across the different course schedules.

H6o: There are no significant differences in the percentage of F's across the different course schedules.

H7o: There are no significant differences in the percentage of Q's across the different course schedules.

To test these hypotheses, a pairwise comparison of the columns in Table 1a must be completed. In other words, each column is compared, one at a time, to each other column to see if there are statistically significant differences in the amounts of A's, B's, C's, D's, F's and Q's in each schedule. Again using a chi-square test, the result of this comparison of column proportions is presented in Table 1c.

Comparisons of Column Proportions(a) of Table 1c

\begin{tabular}{|c|c|c|c|c|}
\hline Course Grade & \multicolumn{4}{|c|}{ Course Schedule } \\
\hline & 1 Day/Week & 2 Days/Week & 3 Days/Week & Summer \\
\hline A & - & - & - & - \\
\hline B & - & - & - & - \\
\hline C & - & - & - & - \\
\hline D & - & - & - & - \\
\hline F & - & - & - & 3 days \\
\hline Q & 3 days & 3 days & 1 day, 2 days, Summer & - \\
\hline
\end{tabular}

Results are based on two-sided tests with significance level 0.05 .

a Tests are adjusted for all pairwise comparisons within a row of each innermost subtable using the Bonferroni correction.

In Table 1c, an entry in a cell represents the course schedule that has a significantly different proportion of that grade than the schedule in that column heading. For example, looking at the one day per week column, the words " 3 days" are in the row labeled Q. This means that the one day per week schedule and the three days per week schedule have rates of Q grades which are significantly different from one another. Similar results are in the two days per week column and the summer column. In the three days per week column, we see that the proportion of Q's for the three days per week schedule is significantly different from all three of the other schedules. In fact, the only grade category (row) for which there is a statistically significant difference between course schedules (an entry in the table) is for the grade of Q. Due to these findings, we must reject the null hypothesis (H7o) and conclude that there is a difference in the rate of $\mathrm{Q}$ grades between course schedules. However, the lack of other significant results indicate that there is no significant difference in the amount of A's, B's, C's, D's or F's in the four schedules. Thus, we cannot reject $\mathrm{H} 2 \mathrm{o}, \mathrm{H} 3 \mathrm{o}, \mathrm{H} 4 \mathrm{o}, \mathrm{H} 5 \mathrm{o}$, or H6o.

These results are based on two-sided tests and therefore do not indicate the direction of the difference in Q's across schedules. However, by looking back at Table 1a, we can see the direction of the difference. Specifically, the three days per week schedule has a higher proportion of Q's than any other schedule. It is noteworthy that while one day per week, two days per week and summer all differ from the three days per week schedule with respect to the $\mathrm{Q}$ rate, they do not differ from one another.

This result is very interesting. Based on prior research and spacing effect theory, one would expect that students in Intermediate Accounting classes, classes which require analysis, are part of a sequence, and require the ability to use prior knowledge, would perform better when taking the course more times per week over longer periods of time. Thus, a course offered three days per week for a long semester should theoretically result in enhanced student learning and therefore in higher performance. However, the results of this study suggest that students in the three days per week schedule are dropping the course at significantly higher rates than students 
taking the course under different schedules. When analyzing this result, it is important to note that at the university being studied, students are permitted to drop a course any time through the last class day of the semester. This results in many students dropping as late as the last day of class to avoid what would otherwise be an F. Thus, at this university, many, if not most, Q's are indicative of an anticipated failing grade, which makes the Q's and F's very similar.

\section{Successful vs. Not successful}

Because of the similarity between the Q and F grades, the next step in this study was to group the Q's and F's together and to compare that group of students to the others. To accomplish this, the grade data was redefined into only two categories, students who were successful and students who were not successful. For purposes of this study, successful is defined as passing the course (earning a grade of A,B,C or D). Students earning an F or Q (failed, dropped, resigned or withdrew) are included in the "not successful" category. After redefining the data in this manner, the first two research questions of this study (and corresponding hypotheses) were addressed a second time, to see if results remain consistent with earlier findings. The original hypothesis (H1o), restated in terms of "success" is as follows:

H80: Student success in Intermediate Accounting is not associated with course schedule.

Table 2a presents the percentage of successful and not successful students in each course schedule.

Table 2a: Success Rates and Course Schedules

\begin{tabular}{|l|c|c|c|c|}
\hline & \multicolumn{4}{|c|}{ Course Schedule } \\
\hline & 1 Day/Week & 2 Day/Week & 3/Day/Week & Summer \\
\hline Not Successful & $23.4 \%$ & $20.7 \%$ & $30.1 \%$ & $19.2 \%$ \\
\hline Successful & $76.6 \%$ & $79.3 \%$ & $69.9 \%$ & $80.8 \%$ \\
\hline
\end{tabular}

The results of the chi-square test of data in Table 2 are presented in Table $2 b$.

Chi-Square Test of Table $2 b$

\begin{tabular}{|l|c|c|c|}
\hline & Value & df & $\begin{array}{c}\text { Significance Level } \\
\text { (p-value) }\end{array}$ \\
\hline Pearson Chi-Square & 11.072 & 3 & .011 \\
\hline
\end{tabular}

The chi-square statistic of 11.072 is significant at a .05 level. This result shows a significant association between course schedule and student success, consistent with previous results. Thus, the null hypothesis, H8o, is rejected. The three days per week schedule has the lowest success rate, followed by the one day per week schedule, then the summer schedule. The two days per week schedule has the highest success rate.

The second research question of this study previously resulted in a set of six hypotheses when individual grades were used as variables. These can be restated into only two null hypotheses now that student success is being used as the variable in question.

H9o: There are no significant differences in the percentage of students who are successful across the different course schedules.

H10o: There are no significant differences in the percentage of students who are not successful across the different course schedules.

To test these hypotheses, again, a pairwise comparison of the proportions of successful/not successful students in each schedule type must be made. To do this, a test of column proportions must be performed. Results are presented in Table 2c. 
Comparisons of Column Proportions of Table 2c

\begin{tabular}{|l|c|c|c|c|}
\hline & \multicolumn{4}{|c|}{ Course Schedule } \\
\hline & 1 Day/Week & 2 Day/Week & 3/Day/Week & Summer \\
\hline Not Successful & - & - & 2 days, Summer & - \\
\hline Successful & - & 3 days & - & 3 days \\
\hline
\end{tabular}

Results are based on two-sided tests with significance level 0.05 .

These results are very similar to previous results. The "not successful" percentage is significantly higher in the three days per week schedule than in the two days per week or summer schedules. Alternatively, the rate of success is higher in the two days per week schedule and in the summer schedule than in the three days per week schedule. Consistent with prior results, the success rates for the one day per week, two days per week and summer schedules are not significantly different from each other. The only new result here is that the difference between the one day per week schedule and the three days per week schedule is no longer statistically significant, although the three day schedule continues to have a higher rate of unsuccessful students.

\section{Effect of Student Characteristics}

The final issue addressed by this study is whether these results will differ depending on student characteristics, specifically age and gender. The third research question of this study addresses student age and can be stated as follows: Is the association between student success and course schedule affected by student age? For purposes of this study, age is defined as traditional and nontraditional. Traditional college-aged students are those who are 25 years old or younger. All students over the age of 25 are considered to be of nontraditional age. This leads to two new null hypotheses.

H110: There is no association between student success and course schedule for students of traditional age.

H120: There is no association between student success and course schedule for students of nontraditional age.

Table 3a presents the percentage of successful/not successful students of each age in each course schedule.

Table 3a: Student Age, Success and Course Schedule

\begin{tabular}{|l|l|c|c|c|c|}
\hline \multicolumn{2}{|l|}{} & \multicolumn{5}{c|}{ Course Schedule } \\
\hline \multicolumn{2}{|l|}{} & 1 Day/Week & 2 Days/Week & 3/Days/Week & Summer \\
\hline Traditional & Not Successful & $29.6 \%$ & $20.9 \%$ & $30.1 \%$ & $19.3 \%$ \\
\hline & Successful & $70.4 \%$ & $79.1 \%$ & $69.9 \%$ & $80.7 \%$ \\
\hline & & & & & \\
\hline Nontraditional & Not Successful & $20.2 \%$ & $20.2 \%$ & $30.8 \%$ & $19.0 \%$ \\
\hline & Success & $79.8 \%$ & $79.8 \%$ & $69.2 \%$ & $81.0 \%$ \\
\hline
\end{tabular}

Next, the chi-square tests were run on each age group separately. The results are presented in Table $3 \mathrm{~b}$.

\begin{tabular}{|l|c|c|c|}
\hline & Chi-Square Tests of Table 3b & Significance level (p-value) \\
\hline Traditional & Pearson Chi-Square Value & df & .010 \\
\hline Nontraditional & $11.276(\mathrm{a})$ & 3 & .613 \\
\hline
\end{tabular}

These results are very interesting. The chi-square statistic is significant for the traditional age students which indicates that there is an association between student success and course schedule for this group. However, the lack of significance for the nontraditional age students indicates that there is no association between course schedule and student success for nontraditional students. Thus, we cannot reject H12o, but we must reject H11o. 
The fourth research question of this study, which addresses student gender, can be stated as follows: Is the association between student success and course schedule affected by student gender? This results in two additional null hypotheses:

H13: There is no association between success rates and course schedule for female students.

H14: There is no association between success rates and course schedule for male students. schedule.

Table 4a presents the percentage of successful/not successful students of each gender in each course

Table 4a: Student Gender, Success and Course Schedule

\begin{tabular}{|l|l|c|c|c|c|}
\hline Gender & \multicolumn{5}{c|}{ Course Schedule } \\
\hline & & 1 Day/Week & 2 Days/Week & 3/Days/Week & Summer \\
\hline Female & Not Successful & $24.1 \%$ & $18.9 \%$ & $28.0 \%$ & $21.4 \%$ \\
\hline & Successful & $75.9 \%$ & $81.1 \%$ & $72.0 \%$ & $78.6 \%$ \\
\hline Male & & & & & \\
\hline & Not Successful & $22.4 \%$ & $22.6 \%$ & $32.1 \%$ & $17.2 \%$ \\
\hline
\end{tabular}

Results of chi-square tests on Table $4 \mathrm{a}$ are presented in Table $4 \mathrm{~b}$.

Chi-Square Tests of Table $4 \mathrm{~b}$

\begin{tabular}{|l|c|c|c|}
\hline \multicolumn{1}{|c|}{ Gender } & Pearson Chi-Square Value & df & Significance level (p-value) \\
\hline Female & $5.360(\mathrm{~b})$ & 3 & .147 \\
\hline Male & & & .040 \\
\hline
\end{tabular}

Once again, the results are quite interesting. The chi-square statistic is not significant for the female subgroup indicating that there is no association between success and course schedule for females. Thus, we cannot reject H13. However, the chi-square is significant for the male sub-group, indicating that there is an association between course schedule and success for male students. Therefore, we must reject H14.

\section{SUMMARY AND INTERPRETATION OF RESULTS}

This research was grounded in spacing effect theory and was designed to investigate the existence of a spacing effect for Intermediate Accounting. To do so, student performance in Intermediate Accounting offered under each of four different schedules was examined. While an association between student performance and course schedule was found, the results are not consistent with spacing effect theory. Results suggest that students in compressed (summer) or intensive (one day per week) schedules perform no differently than do students in a two days per week schedule, which is consistent with the conclusions of Daniel (2000) and Scott \& Conrad (1991). Of particular interest was the finding that students in the three days per week schedule were significantly less successful in Intermediate Accounting than students in any other schedule. However, for the other three schedules, course schedule did not seem to be associated with student performance. This suggests, contrary to the spacing effect, that the three days per week schedule is not a good way for students to take Intermediate Accounting.

What are the possible explanations for this finding? One possibility is that the length of each class session in the three days per week schedule may be too short for Intermediate Accounting. Because the class meets three times per week, each meeting is only 50 minutes long. This may actually represent only about 40-45 minutes of quality instruction time. Perhaps, for Intermediate Accounting and its more complex topics, students need longer time per session to absorb the material or perhaps the teachers need longer time to adequately teach and illustrate the 
concepts without interruption. Dividing these topics into shortened segments may actually be a very inefficient way of learning and/or teaching this subject. Testing over intermediate accounting topics in a 50 minute period may also be problematic. As the topics get more complex and require more analysis and critical thinking, it may be more difficult for students to perform well in such a short time period. These issues may not exist for some courses, such as principles of accounting, where the concepts are simpler (see prior research) but may be very significant for more advanced and complex topics, such as are found in Intermediate Accounting.

Another possibility is that since there is less time between class meetings, students may be less likely to get homework completed and practice new skills before the next class session, which would make it more difficult to master the course material. Alternatively, perhaps the three days per week schedule results in a greater amount of student absenteeism. This could be due to two reasons. First, by offering the material in smaller bites, students may perceive each class as less important and tend to skip class more often. Secondly, the more often a class meets, the chance of missing class due to illness, emergency, etc. are increased. Finally, it is possible that weaker or less motivated students may be self-selecting into the three days per week schedule, although it is unclear as to why this would take place.

Additional findings of this research centered on the effect of student characteristics. Interestingly, this research found that course schedules were associated with student success for males, but not for females. In addition, this association was also found to exist for traditional college age students, but not for older, nontraditional college age students.

Why should student age or gender affect the association between course schedule and success in Intermediate Accounting? Both factors may be related to the overall maturity of the student. Age is clearly directly related to maturity and it has long been believed that males mature later in life than do females. Thus, it may be that both of these variables are acting as a proxy for student maturity. The immature student is more likely to have difficulty dealing with the inefficiencies and interruptions in instruction that occur in a 50 minute class, is more likely to miss class, and is less likely to get homework completed before the next class.

In summary, the three days per week schedule appears least likely to lead to student success in Intermediate Accounting at this university, particularly for the young, male student. The issue of whether these results hold for other universities is a question for future research. In addition, future research should address whether this result will hold for other upper level accounting courses or for upper level college courses in general. These results should be of interest to university administrators responsible for making scheduling decisions, to faculty members teaching under different course schedules, and to individual students planning their class schedules.

\section{AUTHOR INFORMATION}

Linda G. Carrington is an Associate Professor of Accounting at Sam Houston State University in Huntsville, Texas. She received her Ph.D. from the University of Maryland, an MBA from the University of Kentucky, and a BBA in Accounting from Eastern Kentucky University. Dr. Carrington is a Certified Public Accountant, licensed in Kentucky.

\section{REFERENCES}

1. $\quad$ Brett, M. (1996). “Teaching Extended Class Periods." Social Education, 6092), 77-79.

2. Brookes, M.C.T. (1985). “Time in Learning: Does Distribution Make a Difference?” Community/Junior College Quarterly, 9, 291-296.

3. Caskey, S.R. (1994). "Learning Outcomes in Intensive Courses." Journal of Continuing Higher Education, 42, 23-27.

4. Daniel, E.L. (2000). “A Review of Time-Shortened Courses across Disciplines.” College Student Journal, 34, 298-306.

5. Dempster, F.N. (1988). "The Spacing Effect: A Case of History in the Failure to Apply the Results of Psychological Research.” American Psychologist, 43, 627-634. 
6. Donovan, J.J., \& Radosevich, D.J. (1999). “A Meta-analytic Review of the Distribution of Practice Effect: Now you see it, now you don't.” Journal of Applied Psychology, 84, 795-805.

7. Doyle, R.J. \& Yantis, J. (1977). "Facilitating Nontraditional Learning: An Update on Research on Evaluation in Intensive Scheduling." Mount Pleasant, MI: Institute for Personal and Career Development.

8. Foma, E. (1983). "Word Processing Text Editing: Massed versus Spaced Practice.” Journal of Studies in Technical Careers, 5, 19-26.

9. Gallo, M.A. \& Odu, M. (2009). "Examining the Relationship between Class Scheduling and Student Achievement in College Algebra." Community College Review, 36 (4), 299-325.

10. Gay, L.R. (1973). "Temporal Position of Reviews and its Effect on the Retention of Mathematical Rules." Journal of Educational Psychology, 64, 171-182.

11. Henebry, K. (1997). "The Impact of Class Schedule on Student Performance in a Financial Management Course." Journal of Education for Business, 73, 114-120.

12. Kanun, C., Ziebarth, E.W. \& Abrahams, N. (1963). "Comparison of Student Achievement in the Summer Term and Regular Quarter." Journal of Experimental Education, 32, 123-132.

13. Kirby-Smith, J.P. (1987). "Effects of Intensive College Courses on Student Cognitive Achievement, Academic Standards, Student Attitudes, and Faculty Attitudes. "Unpublished Doctoral Dissertation, University of Southern California.

14. Krug, D., Davis, T.B., \& Glover, J. A. (1990). "Massed Versus Distributed Repeated Reading: A Case of Forgetting Helping Recall?” Journal of Educational Psychology, 82, 366-371.

15. Logan, R. \& Geltner, P. (2000). "The Influence of Session Length on Student Success." (Research Report 2000.4.1.0). Santa Monica, CA: Santa Monica College, Office of Institutional Research. Retrieved from http://www.smc.edu/research/T20000410.htm.

16. Petrowsky, M.C. (1996). "The Two Week Summer Macroeconomics Course: Success of Failure?" Glendale, AZ: Glendale Community College. ERIC No. ED396779.

17. $\quad$ Pyle, W.H. (1913). "Economical Learning." Journal of Educational Psychology, 3, 148-158.

18. Reynolds, J. H., \& Glaser, R. (1964). "Effects of Repetition and Spaced Review upon Retention of a Complex Learning Task." Journal of Educational Psychology, 55, 297-308.

19. Scott, P.A. (1996). "Attributes of High-Quality Intensive Course." College Student Journal, 30, 69-77.

20. Scott, P.A. \& Conrad, C.F. (1991). "A Critique of Intensive Courses and an Agenda for Research." Madison, WI: Division of Summer Sessions and Inter-college Programs, University of Wisconsin. ERIC No. ED337097.

21. Seamon, M. (2004). "Short- and Long-Term Differences in Instructional Effectiveness between Intensive and Semester-Length Courses." Teachers College Record, 106, 852-874.

22. Smith, S.M., \& Rothkopf, E.Z. (1984). "Contextual Enrichment and Distribution of Practice in the Classroom." Cognition and Instruction, 1, 341-358.

23. Studdard, A.L., Jr. (1975) "A Study Comparing a Regular Semester and an Interim Term College Level Physical Science Course Based on changes in Student Attitudes and Understanding of Science Processes.” Doctoral Dissertation, University of Alabama. Dissertation Abstracts International, 36, 7979.

24. Wallace, J.A. (1972). "Three Weeks Equals Thirty Weeks? A Report on the Experimental Intensive January Language Course." Foreign Language Annals, 6, 88-94.

25. Van Scyoc, L.J. \& Gleason, J. (1993). "Traditional or Intensive Course Lengths? A Comparison of Outcomes in Economics Learning." Journal of Economic Education, 24, 15-22. 